Józef Stala

The Pontifical University of John Paul II in Cracow, Poland

\title{
Die Freiheit - das besondere Kennzeichen einer modernen Jugenderziehung
}

\section{Freedom - a Special Sign of Youth Modern Education}

\begin{abstract}
The author of the article struggles with a paradox: the post-modern age which views itself as pluralistic nonetheless appears to yearn for upbringing. At the beginning of XXI century, the dissonance between human development, full participation in a wide range of spiritual culture and a tendency to strictly technical education, oriented mainly on efficiency and profits appears in a full range. In this context it is important to educate young people in the responsible use of the gift of freedom. The author of this article presents freedom as a characteristic sign of youth education in the present century. He also shows the pluralism of values and upbringing aimed towards freedom. The author also underlines the Christian approach to freedom, understood as both a gift and a task received from God. Pedagogy of freedom is not a question of transmitting human knowledge, even of the highest kind; it is rather a question of responsibly communicating with God and people. God Himself used a pedagogy that must continue to be a model for the pedagogy of freedom.
\end{abstract}

\section{Keywords}

Upbringing, youth, freedom.

„Dank seiner Seele und seiner geistigen Verstandes- und Willenskraft ist der Mensch mit Freiheit begabt, die ein erhabenes Kennzeichen des göttlichen Bildes im Menschen ist"'. Erziehung und Bildung im wahrhaften Sinn sollen den gesamten Menschen umfassen, also sein physisches

\footnotetext{
1 Katechismus der Katholischen Kirche 1705.
} 
Leben, seine intellektuelle Aktivität, sein emotionales Gefühlsleben und schließlich auch seine Befähigung, das Gute zu wählen und die angestrebten Ziele $\mathrm{zu}$ verwirklichen. Deshalb muss das erzieherische Handeln auf eine integrale Konzeption des Menschen ausgerichtet $\operatorname{sein}^{2}$. Dies ist von besonderer Bedeutung im Hinblick auf die Erziehung und Bildung von Jugendlichen zu Beginn des 21. Jahrhunderts, wo sich eine Diskrepanz zwischen der Entwicklung des Menschen, seiner umfassenden Teilnahme an der breiten Palette der geistigen Kulturgüter (intellektueller, sittlicher, ästhetischer und religiöser Ausprägung) einerseits und der Tendenz zu einer strikt technischen Erziehung andrerseits bemerken lässt, die einzig auf Effektivität und Gewinn ausgerichtet ist ${ }^{3}$. Im aktuellen gesellschaftlichkulturellen Kontext scheint es von immensem Gewicht zu sein, die jungen Menschen dahingehend zu erziehen, dass diese das Geschenk der Freiheit verantwortungsbewusst gebrauchen. Darum wird in dem vorliegenden Artikel die Freiheit als herausragendes Kennzeichen der Jugenderziehung an der Schwelle zum neuen Jahrhundert erörtert. Dabei wird zunächst auf den Pluralismus der Werte in der modernen Welt sowie auf die Erziehung zur Freiheit verwiesen, bevor das Problem der Selbsterziehung und die Freiheit im christlichen Sinn - dem Menschen von Gott geschenkt und als Aufgabe anvertraut - thematisiert werden.

2 Vgl. Gravissimum educationis 3; Apostolicam actuositatem 11; Gaudium et spes 52; Catechesi tradendae 16; J. Stala, E. Osewska, Sociological Aspects of Family Religious Education in Poland, in: Religious Education / Catechesis in the Family. A European Perspective, Hrsg. E. Osewska, J. Stala, Warszawa 2010, S. 167-177; H. Lombaerts, E. Osewska, The Modern Christian Family as a First Setting for Religious and Moral Education?, in: Religious Education/ Catechesis in the Family: A European Perspective, Hrsg. E. Osewska, J. Stala, Warszawa 2010, S. 11-25; J. Wilk, Rodzina jako podstawowe środowisko wychowawcze w świetle doktryny Kościoła Katolickiego, in: Pedagogika katolicka. Zagadnienia wybrane, Hrsg. A. Rynio, Stalowa Wola 1999, S. 292; P. Duksa, Strategie skuteczności szkolnego nauczania religii w Polsce. Studium pedagogicznoreligijne w wymiarze interdyscyplinarnym, Olsztyn 2007.

3 Vgl. Gravissimum educationis 3; Apostolicam actuositatem 11; Gaudium et spes 35 und 52; Catechesi tradendae 36; Jan Paweł II, Chrystus a sens życia człowieka i jego pracy. Do Polaków w Szwajcarii, Sion 17 VI 1984, in: Papież Jan Pawet II. Przemówienia do Polonii i Polaków za granica 1979-1987, Hrsg. R. Dzwonkowski, Londyn 1988, S. 28; E. Osewska, Edukacja religijna w szkole katolickiej w Anglii $i$ Walii w świetle ,Living and Sharing Our Faith. A National Project of Catechesis and Religious Education", Tarnów 2008; E. Osewska, To Educate in a Diversified Europe, "The Person and the Challenges" 1 (2011) Nr. 1, S. 72-73; J. Majka, Wychowanie personalistyczne - wychowaniem integralnym, in: Człowiek-wychowanie-kultura, Hrsg. F. Adamski, Kraków 1993, S. 103-104. 


\section{Der Pluralismus der Werte}

In den traditionellen Gesellschaften gab es ein allgemein angenommenes und akzeptiertes System von Werten, die als wahr anerkannt waren und der nachfolgenden Generation durch die Familie, die Kirche, die Schule, durch andere Erziehungs- und Bildungsinstitutionen sowie durch die gesamte Gesellschaft weiter gegeben wurden. In den postmodernen Gesellschaften (insbesondere in der Europäischen Union und in den USA) veränderte sich diese Situation auf drastische Weise, denn das traditionelle Wertesystem wurde durch einen Pluralismus der Werte und Normen ersetzt. Pluralismus setzt Vielfalt, Unterschiedlichkeit und Konkurrenzdenken voraus, er ist ein Fakt, der nicht zu übergehen ist. Zum einen kann er die Ursache für Unsicherheit und Unruhe sein, zum anderen eröffnet er bestimmte neuartige Möglichkeiten, wie die Erfahrung der eigenen Individualität und der Wahlfreiheit. In einer pluralistischen Gesellschaft präsentieren Institutionen, Organisationen, Gruppen, Bewegungen, Vereinigungen und die Massenmedien die unterschiedlichsten Werte, darunter auch Pseudowerte und Antiwerte ${ }^{4}$.

Im Kontext der modernen Zivilisation, die gegenwärtig eine Krise durchlebt, welche sich vor allem in der Krise der Werte widerspiegelt, ist es unerlässlich, den Fragenkreis zum Thema von Erziehung und Bildung zu betrachten $^{5}$. In welche Richtung geht der Erziehungs- und Bildungsprozess bei Kindern und Jugendlichen? Wer präsentiert die Freiheit und auf welche Art und Weise? Wodurch ist eine reife und verantwortungsvolle Freiheit gekennzeichnet? Wie vollzieht sich die Erziehung der jungen Menschen, damit diese eine Werteauswahl treffen können? Wie gestaltet sich die Freiheit? Vor der Beantwortung dieser Fragen muss man sich bewusst werden, dass der Jugendliche je nach der Fortentwicklung der Zivilisation heute den vielfältigsten Einflüssen ausgesetzt ist: nicht mehr nur dem der Familie, der Schule und der Kirche sondern auch dem von Presse, Radio, Fernsehen (vor allem Musik- und Jugendsendern), Internet, Supermärkten,

4 Vgl. H. Lombaerts, Komunikacja wiary dzisiaj, in: Komunikacja wiary w Trzecim Tysiacleciu, Hrsg. S. Dziekoński, Olecko 2000, S. 25-39; E. Osewska, W poszukiwaniu modeli wychowania młodzieży ku wartościom, in: Katechizować dzisiaj. Problemy i wyzwania, Hrsg. J. Stala, Kielce 2004, S. 193-209.

5 Vgl. J. Mariański, Johannes Paul II. als moralische Autorität in der polnischen Gesellschaft, “The Person and the Challenges" 2 (2012) Nr. 1, S. 21-50; G. Gill, Moral Leadership in a Postmodern Age, Edinburgh 1997, S. 109-122. 
Sportstadien, Kino, Diskotheken und anderen Jugendtreffpunkten. Folglich ist der Grundsatz von Impuls und Reaktion hier zu einfach gedacht. Eltern, Erzieher und Lehrer sind weder imstande, die Jugendlichen vor allen Gefahren zu schützen, noch diese vollständig von negativen Einflüssen abzuschirmen. Aber sie können die vorliegende Situation gemeinsam analysieren und zusammen nach der Wahrheit über den Menschen, die Erziehung und die Werte suchen. Ebenso können sie den jungen Menschen auf dem Weg seiner Erziehung zur Freiheit begleiten und sich darum bemühen, dass dieser klug und verantwortungsbewusst von dem Geschenk der Freiheit Gebrauch machen kann. Erziehung und Bildung sollen den jungen Menschen darauf vorbereiten, diejenigen Werte auszuwählen, auf deren Grundlage er in der Zukunft verantwortungsvoll handeln kann. Wenn das erzieherische Wirken nicht in diesem Sinn erfolgt, lässt sich nur schwerlich von einer psychischen Reife des Menschen sprechen, die sich darin ausdrückt, dass er in Übereinstimmung mit den anerkannten Normen leben, Verantwortung für seine Taten übernehmen und sich wahrhaft seines Nächsten annehmen kann ${ }^{6}$.

\section{Die Erziehung zur Freiheit}

In der heutigen Zeit besteht eine der wesentlichsten Aufgaben von Erziehung undBildunginderErziehungzurFreiheit. DiesozialeDimension derFreiheithängt von der Reife des individuellen Bürgers ebenso ab wie von seiner Vorbereitung auf den Gebrauch der Freiheit und auf das Freisein. Die Freiheit, die bereits in der menschlichen Person verwurzelt ist und deren vielfältige Entwicklung bedingt, gehört zu den fundamentalen und unerlässlichen Menschenrechten. Von daher ist es notwendig, vor einer Freiheit zu warnen, die lediglich dem Anschein nach besteht, die oberflächlich und einseitig verstanden wird und nicht von der ganzen Wahrheit über den Menschen und die Welt durchdrungen ist ${ }^{7}$. Der Mensch der Gegenwart lebt zweifellos in der Überzeugung, dass er ein

\footnotetext{
6 Vgl. Familiaris consortio 18; Brief an die Familien: Gratissimam sane 16.

7 Vgl. Redemptor hominis 12; Veritatis splendor 17; Evangelium vitae 19-20; A. Skreczko, Rola Kościoła katolickiego w ksztattowaniu kultury pedagogicznej rodziców w Polsce, Białystok 2011; B. Kl’uska, Idea chrześcijańskiego nawrócenia w procesie resocjalizacji, in: Socjalizacja - wyzwanie wspótczesności, Hrsg. J. Stala, Tarnów 2010, S. 75-87; T. Ożóg, Kulturowe zagrożenie wychowania, in: Wychowanie chrześcijańskie a kultura, Hrsg. M. Nowak, T. Ożóg, Lublin 2000, S. 167-188; F. Adamski, Edukacja, rodzina, kultura. Studia z pedagogiki spotecznej, Kraków 1999, S. 20-23; L. Giussani, Wychowanie do wolności, in: Pedagogika katolicka. Zagadnienia wybrane,
} 
Wesen ist, welches in freier Wahl über die Art und Weise entscheiden kann, wie er das eigene Leben verwirklichen will. Dabei vergisst er leider nur zu oft, dass dieses Geschenk der Freiheit mit der Verantwortung verknüpft ist, dieses auch im guten Sinn zu gebrauchen. Im Kontext der modernen Mentalität, im Namen der Freiheit jegliche Autorität zu negieren, wird der verantwortungsvolle Umgang mit der Freiheit zu einem Problem. Damit die wahre Freiheit erlangt werden kann, muss sie als eine Herausforderung betrachtet werden, die sich jedem Menschen stellt. Die Freiheit des Menschen als Entscheidungsfähigkeit ist ein großes Geschenk, dem der Mensch niemals entsagen kann. Gleichzeitig jedoch kann die Freiheit zu keiner Zeit willkürlich sein. Zur Freiheit zu erziehen bedeutet, den Menschen dahin zu führen, dass er von der Wahrheit fasziniert ist und sie bereitwillig annimmt ${ }^{8}$.

Die Freiheit reift und festigt sich in dem Maß, in welchem die Persönlichkeit reift. Gerade in der Phase der Jugend, in der sich vielfältige Wandlungen vollziehen, wächst sie heran und formt sich aus. Gewaltige Veränderungen, die besonders den ersten Abschnitt der Adoleszenz charakterisieren, treten ebenso im biologischen, im psychischen wie auch im sozialen Bereich auf. Die Begleiterscheinungen des Heranwachsens stellen einen außerordentlich stürmischen Prozess dar und werden sowohl für die unmittelbar davon Betroffenen zu einer zu einer schwierigen Zeit als auch für ihre Umgebung: die Eltern, die älteren Geschwister, die Lehrer und Erzieher, welche das Eintreten des Jugendlichen in das Erwachsenenleben beobachten und mittragen?.

Hrsg. A. Rynio, Stalowa Wola 1999, S. 184-189; S. Rosik, Czy Kościót lęka się wolności?, in: Problemy współczesnego Kościoła, Hrsg. M. Rusecki, Lublin 1997, S. 423-433.

8 Vgl. Redemptor hominis 12 und 16; Veritatis splendor 17; Evangelium vitae 19-20; K. Wojtyła, Rozważania o istocie człowieka, Kraków 1999, S. 63-71; J. Stala, Der Mensch als Person: Die bestimmende Grundlage für Johannes Paul II. in seinem Bild von der Familie, "The Person and the Challenges" 2 (2012) Nr. 2, S. 41-59; J. Stala, Die Transzendenz als bestimmendes Merkmal der Person in der Anthropologie und der Pädagogik Johannes Pauls II., „The Person and the Challenges" 2 (2012) Nr. 1, S. 61-75; J. Wilk, Pedagogika rodziny. Zagadnienia wybrane, Lublin 2002, S. 166-168; I. Dec, Blask prawdy w wolności i wolności w prawdzie, in: W prawdzie ku wolności. W kręgu encykliki Veritatis splendor, Hrsg. E. Janiak, Wrocław 1994, S. 113-115.

9 Vgl. E. Osewska, L'educazione oggi in un'Europa diversificata, in: Europa, scuola, religioni. Monoteismi e confessioni cristiane per una nuova cittadinanza europea, Hrsg. F. Pajer, Torino 2005, S. 47-64; E. Osewska, Modele komunikacji interpersonalnej i ich znaczenie dla katechezy, in: Wybrane zagadnienia z katechetyki, Hrsg. J. Stala, Tarnów 2003, S. 111-142; E. Osewska, Możliwości i ograniczenia polityki rodzinnej w krajach Unii Europejskiej, in: Rodzina jako środowisko rozwoju człowieka, Hrsg. W. Piotrowski, Tarnów 2004, S. 89-119; E. Osewska, Wychowaniemłodzieżywświetle Programu PolitykiRodzinnejpaństwa, in:Dzisiejszybierzmowany. Problemy i wyzwania, Hrsg. J. Stala, Kielce 2005, S. 455-466; E. Osewska, Wspótczesna młodzież, 
Die Vertiefung des Wissens und die Fertigkeiten Erwachsener machen zweifellos einen wesentlichen Faktor aus, der sich positiv auf den weiteren Lebensverlauf des jungen Menschen auswirkt. Dabei können nicht nur passende Erziehungsprogramme eine wichtige Rolle spielen. Vielmehr kann jede Begegnung zu einer Chance werden, mit dem Jugendlichen im Prozess seiner psychischen, sozialen und religiösen Bildung zusammen zu arbeiten. Dank entsprechender Erziehungs- und Bildungsangebote können die Jugendlichen den Wert der Freiheit und deren Bedeutung im täglichen Leben entdecken ${ }^{10}$.

Eine reife Freiheit besteht nicht in Willkür, Anarchie und totaler Unabhängigkeit sondern bedeutet die Wahl des Guten auf schöpferische und verantwortungsvolle Weise, sie ist also von Grund auf personalistisch ${ }^{11}$. Das Bild der menschlichen Freiheit bleibt nicht blind für ihre Einschränkungen und Aberrationen. Der Mensch kann seine Freiheit auf das Gute hin ausrichten, er kann sich jedoch dank seiner Freiheit auch vom Guten abwenden. Derzeit können sich viele junge Menschen, die ihre Freiheit eher im schlechten Sinn gebrauchen, dem konsumorientierten Lebensstil nicht widersetzten. Es ist zu bedenken, dass jeder Mensch gleichermaßen von den Eigenschaften und der Leistungsfähigkeit seines Körpers abhängig ist, von seiner genetischen Disposition, vom Einfluss seiner Erziehung, von seiner Rassen- und Volksangehörigkeit, vom Klima, von der Kultur, von der Tradition und den Gebräuchen. In einem gewissen Sinn wird die Freiheit des Menschen weiter eingeschränkt durch den Druck unterschiedlicher gesellschaftlicher Gruppen, durch Manipulation, Propaganda, Indoktrination, Alkohol- und Drogenmissbrauch. In seinem Handeln jedoch

in: Dzisiejsza młodzież, Hrsg. J. Stala, Tarnów 2001, S. 241-246; J. Homplewicz, Pedagogika rodziny. Zarys wykładów na podyplomowym studium prorodzinnym, Rzeszów 2000, S. 115.

${ }^{10}$ Vgl. G. Rossiter, Reasons for Living. Religious Education and Young People's Search for Spirituality and Identity, in: Religious Education as Practical Theology, Hrsg. B. Roebben, M. Warren, Leuven-Paris-Sterling 2001, S. 95; E. Osewska, Uwarunkowania wychowania religijnego w rodzinie, in: W kręgu rodziny, Hrsg. E. Osewska, J. Stala, Poznań 2003, S. 13-21; J. Stala, E. Osewska, Anders erziehen in Polen. Der Erziehungs- und Bildungsbegriff im Kontext eines sich ständig verändernden Europas des XXI. Jahrhunderts, Tarnów 2009.

${ }^{11} \mathrm{Vgl}$. H. Lombaerts, E. Osewska, Historical and Geo-Political Reality of a United Europe, in: S. Gatt, H. Lombaerts, E. Osewska, A. Scerri, Catholic Education, European and Maltese Perspectives. Church School's response to future challenges, Floriana 2004, S. 27-43; Hermeneutics and Religious Education, Hrsg. H. Lombaerts, D. Pollefeyt, Leuven-Paris-Dudley 2004; H. Lombaerts, Edukacja z perspektywy europejskiej, „Horyzonty Wychowania” (2002) Nr 2, S. 165-179; M. Majewski, Aktualne wyzwania katechetyczne, Kraków 1997, S. 24; S. Rosik, Czy Kościót lęka się wolności?, in: Problemy współczesnego Kościoła, Hrsg. M. Rusecki, Lublin 1996, S. 430; J. Majka, Wychowanie personalistyczne - wychowaniem integralnym, in: Człowiekwychowanie-kultura, Hrsg. F. Adamski, Kraków 1993, S. 99. 
ist der Mensch frei, da er sich letztendlich selbst auf bewusste Art und Weise lenkt. Folglich muss es im Rahmen der Vorschläge für Erziehung und Bildung wesentlich sein, die Freiheit als großes aber auch problembehaftetes Geschenk aufzuzeigen $^{12}$.

\section{Von der Erziehung zur Freiheit hin zur Selbsterziehung}

Vom Anbeginn seines Lebens an, von seiner Geburt bis zu seinem natürlichen Tod, unterliegt der Mensch bestimmten Prozessen. Zunächst ist er vollständig davon abhängig, dass sich andere Menschen um ihn kümmern und ihn versorgen. Später entwickelt sich jedoch sein Bestreben, mehr als eigenständige Person und nach außen orientiert zu leben, womit die Grundlage für seine Selbsterziehung gelegt wird ${ }^{13}$. Dieser Prozess stellt die natürliche Konsequenz einer wahrhaften Erziehung dar, zu selbsterzieherischem Handeln ist der Mensch jedoch von der Vorschule bis zu den späten Jahren seines Lebens fähig. Die Anstrengungen in diesem Bereich sind proportional zum Alter des Menschen und zu seiner psycho-physischen Disposition. Diese Arbeit an sich selbst endet nie, da sie darin besteht, sich seinem Idealbild langsam und immer bewusster anzunähern. Das Heranführen an die Selbsterziehung ist in der Phase des Heranwachsens von besonderer Bedeutung, in welcher der Jugendliche lernt, verantwortungsvolle und selbstständige Entscheidungen zu treffen, seinen Charakter auszubilden und seine Lebenseinstellung zu formen. Vor allem in Bezug auf die jungen Menschen muss man sich bewusst werden, wie wichtig die Selbsterziehung ist, da der Jugendliche

12 Vgl. Veritatis splendor 17; Redemptor hominis 12; Familiaris consortio 6; G. Davie, Europe: The Exceptional Case. Parameters of Faith in the Modern World, London 2002; Religion in Contemporary Europe, Hrsg. J. Fulton, P. Gee, Lewiston-Queenston-Lampeter 1994; F. Adamski, Integralna wizja kultury u podstaw chrześcijańskiego wychowania, in: Wychowanie chrześcijańskie a kultura, Hrsg. M. Nowak, T. Ożóg, Lublin 2000, S. 9-14; L. Gussani, Wychowanie do wolności, in: Pedagogika katolicka. Zagadnienia wybrane, Hrsg. A. Rynio, Stalowa Wola 1999, S. 183-189; A. Gałdowa, Wprowadzenie, in: Wybrane koncepcje osobowości, Hrsg. A. Gałdowa, Kraków 1995, S. 5-28; L. Balter, Chrystologiczne podstawy humanizmu, in: Tajemnica człowieka. Wokót osoby i myśli ks. Wincentego Granata, Lublin 1985, S. 293-315.

${ }_{13}$ Vgl. Pastores dabo vobis 44; Brief an die Familien: Gratissimam sane 16-17; E. Prijatelj, Geistige Dynamik von Vorschulkindern und deren Einführung in den Glauben, „Christlich pädagogische Blätter” (2007) Nr. 2, S. 100-104; E. Prijatelj, Psihološka dinamika rasti v veri, Ljubljana 2008; B. Bilicka, Kościół $w$ polskich katechizmach i podręcznikach do nauki religii dla dzieci i młodzieży w latach 1945-2001, Toruń 2009; Wychowanie do wartości w świecie cyberkultury, Hrsg. B. Bilicka, Toruń 2012. 
durch die Selbsterziehung den von ihm anerkannten Vorbildern gleichen und sich die Charakterzüge aneignen will, die es ihm ermöglichen, sich seinen Idealen anzunähern. Die Selbsterziehung ist als Grundbedingung für ein Leben als Person anzusehen, denn die naturgegebenen Dispositionen des Menschen erlauben es ihm sich selbst zu verwirklichen. Damit sind auch die Ausformung der persönlichen Reife des Menschen, seine Opferbereitschaft und die Anerkennung seiner Fehler verknüpft ${ }^{14}$. Dennoch darf nicht vergessen werden, dass jeder Mensch trotz der vielfältigen Beschränkungen die Möglichkeit hat vollkommen zu werden. Daher soll kein Mensch jemals seine eigenen Aspirationen herabsetzten, den maximal erreichbaren Ziele ausweichen und sich stattdessen mit dem unentbehrlichen Minimum zufrieden geben. Ein bedeutender Faktor für eine gelungene Selbsterziehung muss die Reife und das Bewusstsein der eignen Persönlichkeit bei allen sein, die den mühevollen Weg dahin auf sich nehmen. Daher kann sich der junge Mensch erst dann wirklich erwachsen fühlen, wenn er imstande ist, die Strapazen einer selbstständigen Persönlichkeitsentwicklung anzugehen. Diese Reife erfordert jedoch vor allem die Selbsterziehung. Kann man sich doch nur schwerlich vorstellen, dass jegliche Form einer Herausforderung ohne eine gewisse Selbstdisziplin zu meistern wäre ${ }^{15}$. Durch die Selbsterziehung tritt der junge Mensch in die problematische, spezifische, aber auch unerhörte Welt der Möglichkeiten ein, die sich ihm eröffnen. Daher muss der Selbsterziehung als Faktor, der bei der Entdeckung neuer Möglichkeiten für den Menschen hilfreich ist, wesentlich mehr Raum gewidmet werden. Dann kann dieser auch ein schweres, jedoch reales Ziel erreichen, das der Anstrengungen wert ist. Besonders in der Lebenssituation des jungen Menschen in der modernen Zeit,

${ }^{14}$ Vgl. P. Rosenthal, Words and Values, New York-Oxford 1984, S. 85-104; A. Skreczko, Troska Kościoła katolickiego $w$ Polsce o matżeństwo i rodzinę w okresie Wielkiej Nowenny Tysiaclecia (1957-1966). Studium teologiczno-pastoralne, Białystok 2002; J. Stala, Familienkatechese in Polen um die Jahrhundertwende. Probleme und Herausforderungen, Tarnów 2008; J. Stala, Wspótpraca rodziny, szkoty i parafii w realizacji zadań wychowawczych, in: Katecheza w parafii. Poszukiwanie tożsamości, Hrsg. K. Kantowski, Warszawa 2004, S. 139-149; J. Stala, Wspótpraca rodziny, szkoły i parafii w dziele wychowania, in: Dydaktyka katechezy. Część I, Hrsg. J. Stala, Tarnów 2004, S. 339-376.

${ }^{15}$ Vgl. A. Gellel, Adaptive Religious Education at the Service of Inventiveness: A scientific way of being creative and effective in Religious Education, "The Person and the Challenges" 1 (2011) Nr. 1, S. 99-111; D. D. Raphael, Moral Philosophy, Oxford 1981; R. S. Downie, Freedom and Determinism, in: A Dictionary of Pastoral Care, Hrsg. A. W. Campbell, London 1993, S. 92-93; J. Vodičar, Muss man die Globalisierung unterrichten?, „Synthesis philosophica” (2009) 2, S. 281295; S. Gerjolj, Ideologie und Bildung, Gießen 1997; N. Bravena, Philosophizing with Children on National Tradition Related to Christmas, in: Symetrical communication? Philosophy and Theology in Classrooms across Europe, Hrsg. F. Kraft, H. Roose, G. Büttner, Loccum 2011, S. 61-74. 
der hier so vielen Gefährdungen begegnet, ist es wesentlich, die positive Rolle der Selbsterziehung nicht nur in ihrer religiösen sondern ebenso in ihrer rein existenziellen, menschlichen Dimension hervor zu heben ${ }^{16}$.

Dabei soll die Selbsterziehung vor allem in der Kategorie einer verantwortungsvollen Aufforderung zur Vollkommenheit aufgezeigt werden, die sich jedem Menschen stellt. Dies bedeutet, die verschiedenen Formen der Selbsterziehung und der Arbeit an sich selbst kennen zu lernen und sich damit auf den Weg zur Vollkommenheit und zum Glück zu begeben. Im Kontext der Erziehung im Rahmen der Familie gilt es darüber hinaus zu bedenken, dass der junge Mensch die Selbsterziehung und die Arbeit an seinem Charakter benötigt. Ein bedeutender Faktor auf der jugendlichen Wanderschaft hin zur Reife ist eben gerade die Selbsterziehung, die für den jungen Menschen eine große Herausforderung darstellt, da er sich selbst oft wenig oder gar nichts abverlangen will. Man kann nicht von einer wahren Reife des Menschen sprechen, wenn dieser sich nicht die Mühe macht, sein eigenes Ich realistisch und kritisch, aber dennoch voller Liebe zu betrachten. Die Arbeit an sich selbst, auf allen Ebenen des menschlichen Lebens - die Bildung und die Vervollkommnung der Fähigkeiten und Fertigkeiten - ist eine außerordentlich fruchtbare Investition des Menschen in sein zukünftiges Glück. In dem langwierigen Prozess, die Jugendlichen zur Selbsterziehung hinzuführen, stellt die personalistische Pädagogik im christlichen Verständnis eine Alternative zu der humanistischen Pädagogik laizistischer Ausprägung dar, welche in der Gesellschaft auf geradezu aggressive Weise propagiert wird. Die personalistische Vision betrachtet den Menschen als eigenständige Person. Als Person ist er dazu befähigt bewusst und frei zu leben, sich und die Welt zu verstehen und sich und der Welt gegenüber eine verantwortungsbewusste Haltung einzunehmen. In der personalistischen Perspektive besteht der letztendliche Sinn des menschlichen Lebens darin, sich selbst in die objektive Geschichte der Liebe und der Wahrheit einzubringen. Jeder Mensch trägt die Sehnsucht nach einer derartigen Welt

${ }^{16}$ Vgl. Veritatis splendor 16-20; A. Szostek, Wokót godności prawdy i miłości, Lublin 1998, S. 28-31 i 117-132; A. Skreczko, Rozwijanie podmiotowości dziecka w rodzinie, in: Podmiotowość we współczesnej edukacji. Oglady - Intencje - Realia, Hrsg. J. Niemiec, A. Popławska, Białystok 2009, S. 55-62; Z. Matulka, Wychowanie do wolności jako podstawowy problem pedagogiczny, in: Pedagogika ogólna. Problemy aksjologiczne, Hrsg. T. Kukołowicz, M. Nowak, Lublin 1997, S. 243-250; J. Krucina, Prawda o człowieku miara wolności, in: W prawdzie ku wolności. W kręgu encykliki Veritatis splendor, Hrsg. E. Janiak, Wrocław 1994, S. 132-142; J. Merecki, T. Styczeń, Veritatis splendor - encyklika o wolności, in: W prawdzie ku wolności. W kręgu encykliki Veritatis splendor, Hrsg. E. Janiak, Wrocław 1994, S. 208-211. 
der Liebe und der Wahrheit in sich. Der Mensch ist jedoch als Person nicht vollkommen, aus theologischer Sicht ist er sogar schwach, verletzbar und durch die verschiedenartigsten Illusionen gefährdet, durch Schlechtes von innen und von außen. Deshalb ist die Erziehung kein spontaner Prozess sondern erfordert die Gegenwart des gereiften Erziehers ebenso wie innere Disziplin und Anstrengungsbereitschaft auf der Seite des Zöglings. Die grundlegenden Werte, auf denen sowohl die Erziehung als auch die Selbsterziehung basieren sollten, stellen die objektive Wahrheit über den Menschen, die Freiheit und eine gereifte Liebe dar ${ }^{17}$.

\section{Die Freiheit - dem Menschen von Gott geschenkt und als Aufgabe anvertraut}

Die Freiheit wurzelt tief in der menschlichen Person und ist die Bedingung für deren Entwicklung auf allen Ebenen. Somit gehört sie zu den fundamentalen und unveräußerlichen Grundrechten des Menschen. Darum hat die Kirche stets mit ganzer Kraft daran erinnert, dass sie dank ihrer göttlichen Mission über die Freiheit wacht, die für die wahrhafte Würde der menschlichen Person unabdingbar is $t^{18}$. Gleichzeitig warnte sie vor einer scheinbaren Freiheit, die nur oberflächlich und einseitig ist und die gesamte Wahrheit über den Menschen und die Welt nicht durchdringt. Allein Jesus Christus bringt dem Menschen eine Freiheit, die auf Wahrheit und Verantwortung gründet ${ }^{19}$.

Wenn man die Probleme berücksichtigt, die der Mensch aktuell dabei hat, seinen ontologischen Status zu bestimmen, lässt sich erkennen, dass er sich wieder die Wahrheit darüber ins Gedächtnis rufen muss, wer er als

${ }^{17} \mathrm{Vgl}$. H. Lombaerts, The Impact of the Status of Religion in Contemporary Society upon Interreligious Learning, in: Interreligious Learning, Hrsg. D. Pollefeyet, Leuven 2007, S. 81-86; H. Lombaerts, ICT jako główne wsparcie globalnego świata i globalnego środowiska edukacyjnego, in: Hrsg. A. Bałoniak, J. Szpet, Między tradycja a współczesnościa, Poznań 2008, S. 73-90; J. Stala, Die Erzieherischen Umfelder und Ihre Rolle im Rahmen der Erziehungsaufgaben, „Studia Teologiczno-Historyczno Śląska Opolskiego" 27 (2007), S. 375-383; J. Stala, Familie und Schule: Zwei Erziehungsumfelder und ihre Rolle im Rahmen der Erziehung, „Roczniki Teologiczne” 55 (2008), Tom 8, S. 101-112.

${ }^{18} \mathrm{Vgl}$. Redemptor hominis 12; Evangelium vitae 20; Veritatis splendor 17.

${ }_{19} \mathrm{Vgl}$. L. Giussani, Wychowanie do wolności, in: Pedagogika katolicka. Zagadnienia wybrane, Hrsg. A. Rynio, Stalowa Wola 1999, S. 184-189; S. Rosik, Czy Kościót lęka się wolności?, in: Problemy wspótczesnego Kościoła, Hrsg. M. Rusecki, Lublin 1997, S. 423-433. 
Person und als Wesen ist, das in der Unterscheidung von „Jemand anderem” existiert ${ }^{20}$. Jedes neugeborene menschliche Wesen ist dazu berufen, als Person zu existieren, die das Vergängliche übersteigt und sich der Ewigkeit in Gott öffnet. Der Mensch - die Person - ist die einzige Kreatur auf der Erde, die Gott um ihrer selbst willen wollte. Die Genesis des Menschen besteht also nicht nur in biologischen Rechten sondern gleichzeitig im schöpferischen Willen Gottes. Die Genealogie der Person ist von Anbeginn an mit der Ewigkeit Gottes verbunden. Erziehung und Bildung müssen sich also immer auf die dynamische Struktur des Menschen und damit auf sein beständiges Werden beziehen. Außerhalb einer wahrhaften familiären Gemeinschaft ist nichts annähernd so gut dazu imstande, dem Kind die Grundlagen für eine derartig umfassende und ganzheitliche Entwicklung seiner eigenen Persönlichkeit zuzusichern ${ }^{21}$.

Das Postulat nach einer harmonischen Erziehung umfasst den ganzen Menschen und die Integralität aller Inhalte, die im Erziehungsprozess übertragen werden. Der zu erziehende Mensch muss in die Gesamtheit der Errungenschaften menschlicher Kultur durch Erziehung und Bildung eingeführt werden, auch ist ihm deren spezifische Hierarchie aufzuzeigen. Die Erziehung darf keines der einzelnen Elemente ausklammern, da sie sonst nicht umfassend und die Entwicklung nicht ganzheitlich wäre. Denn der Mensch ist, wie Johannes Paul II. bekräftigte, ein geistig-materielles Individuum, eine Person und eine Persönlichkeit, die sich in der natürlichen ebenso wie in der übernatürlichen Sphäre aktualisiert ${ }^{22}$.

Aus christlicher Sicht kann man einen Bezug zur Beschränkung der menschlichen Freiheit finden, insbesondere zur Ratlosigkeit des Menschen gegenüber der Sünde. Die Freiheit ist vor allem im Kontext der dem Menschen zueigenen Personenwürde zu verstehen, bei der die Freiheit einen der wichtigsten Aspekte darstellt, auch im Fall, dass es zu Problemen mit den

${ }^{20}$ Vgl. Cz. Bartnik, Personalizm, Lublin 1995, S. 189.

${ }^{21}$ Vgl. Gaudium et spes 24; Brief an die Familien: Gratissimam sane 9; J. Bagrowicz, Edukacja religijna wspótczesnej młodzieży. Źródta i cele, Toruń 2000, S. 112; W. Stróżewski, O stawaniu się człowiekiem, (Kilka myśli niedokończonych), in: Człowiek-wychowanie-kultura, Hrsg. F. Adamski, Kraków 1993, S. 52; J. Majka, Wychowanie personalistyczne - wychowaniem integralnym, in: Człowiek-wychowanie-kultura, Hrsg. F. Adamski, Kraków 1993, S. 96.

${ }^{22}$ Vgl. Jan Paweł II, Chrystus a sens życia człowieka i jego pracy. Do Polaków w Szwajcarii, Sion 17 VI 1984, in: Papież Jan Pawet II. Przemówienia do Polonii i Polaków za granica 19791987, Hrsg. R. Dzwonkowski, Londyn 1988, S. 28; Jan Paweł II, Kształtowanie dojrzałego człowieczeństwa. Do profesorów i studentów Katolickiego Uniwersytetu Lubelskiego. Jasna Góra, 6 czerwca 1979, in: Jan Pawet II. Musicie od siebie wymagać, Poznań 1984, S. 145-146. 
204 Volume 3 (2013) Number 2, p. 193-207

unveräußerlichen Menschenrechten kommt. Die Frage nach der Freiheit muss im Zusammenhang mit der Verantwortung des Menschen für seine Freiheit stehen. In dieser Bedeutung besteht die Krönung der Freiheit in einer Freiheit, welche die Kinder Gottes charakterisiert und der konsequenten Antwort auf die Aufforderungen Jesu Christi entspringt. Wenn der Mensch also auf dem Weg zur christlichen Vollkommenheit voranschreiten will, ist er dazu aufgerufen, Antworten auf das Rufen Jesu Christi zu geben, welcher „der Weg, die Wahrheit und das Leben" ist. Der Mensch befindet sich fast in jedem Augenblick an einer Kreuzung und ist dazu verurteilt, eine Wahl treffen zu müssen, die wesentlichen Einfluss auf seine Zukunft haben kann. Diese Verurteilung zu unaufhörlicher Wahl hat ihre Quelle in der menschlichen Natur, die von Gott mit Freiheit beschenkt ist. Obwohl Gott deutliche Hinweise für ein moralisch gelungenes Leben gibt, schränkt er den freien Willen des Menschen jedoch niemals ein sondern fordert lediglich, die Verantwortung für diese Freiheit zu übernehmen. Gleichzeitig kann man dieser Freiheit nicht entsagen, da sie ein grundlegendes Attribut der Menschlichkeit darstellt ${ }^{23}$.

Weiterhin bleibt zu bedenken, dass der Mensch für das Geschenk der Freiheit verantwortlich ist vor Dem, der den Menschen unablässig mit dieser Freiheit beschenkt - seinem Schöpfer. Denn Er befreit den Menschen durch Jesus Christus zur geistigen Freiheit, zur „Freiheit der Kinder Gottes”, ohne immerfort seine äußerlichen Bedingtheiten einzubeziehen. Der von Gott befreite Mensch kann sich auch dann frei fühlen, wenn er in Gefangenschaft lebt. Christus ist in die Welt gekommen, um den Menschen zu erlösen. Durch Ihn wurde der Mensch befreit. Christus, der die Freiheit des Menschen stets berücksichtigte, zwang niemals Jemanden zu etwas sondern verwies lediglich auf die wesentlichen Werte im menschlichen Leben, gab Unterstützung dabei, die richtige Wahl zu treffen und rief dazu auf, bis in die Tiefe über sich selbst nachzudenken. Viele Erscheinungsformen des Bösen, die sich in der heutigen Welt wahrnehmen lassen, kann man mit dem Begriff einer Zivilisation des Todes beschreiben und gehen daraus hervor, dass der Mensch das Geschenk der Freiheit in einem falschen Sinn versteht. In diesem Kontext soll Christus als Derjenige vorgestellt werden, der dem Menschen Rettung und wahre Freiheit bringt ${ }^{24}$.

${ }^{23}$ Vgl. E. Osewska, Le pèlegrinage à Czestochowa. Lieu d'éducation dans la foi, « Lumen Vitae Revue » (2007), S. 247-265.

${ }^{24}$ Vgl. Gaudium et spes 17; Redemptor hominis 12. 
Der vorrangige und fundamentale Faktor der christlichen Erziehung zur Freiheit ist ihre authentisch menschliche Dimension. Dies umfasst zum ersten die wachsende Fähigkeit, Erscheinungen, Situationen und Lebenskonzeptionen kritisch zu hinterfragen und zu bewerten, die in einer pluralistischen Gesellschaft durch die unterschiedlichen Lebensumfelder verbreitet werden. Zweitens gehören dazu alle denkbaren Hilfestellungen, damit der heranwachsende Mensch eine eigene Weltanschauung ausbilden, den Sinn des Lebens entdecken und eine Wertehierarchie festlegen kann. Zum dritten unterstützt die Erziehung die Aspirationen der Jugendlichen im Hinblick auf den Aufbau einer menschlicheren Welt, die frei von Verfolgung und Gewalt ist und die auf Achtung und Wertschätzung der verschiedenartigen Personen und ihrer Überzeugungen basiert. Dagegen betrifft der zweite Faktor der christlichen Erziehung zur Freiheit ihre ontologische und theologische Dimension, womit sich ihre spezifisch christliche Ausprägung bestätigt. Kraft seines Glaubens und des Sakraments der Taufe wird der Christ dem Sohn Gottes, Jesus Christus, ähnlich, indem er sich unablässig bekehrt und im Glauben, in der Hoffnung und in der Liebe wächst. Das Ziel dieses Prozesses sind die Freiheit der Wahl und die Realisierung der Vollkommenheit in Christus sowie die eigene Heiligkeit. Wahre menschliche Reife bildet die Basis und das Fundament für authentische christliche Reife. Die Erziehung im Glauben stellt einen Prozess dar, der sich nicht nur auf das Evangelium und das Leben der Kirche stützt sondern auf den natürlichen Bedingungen der menschlichen Entwicklung aufbaut.

\section{Bibliography}

Adamski F., Edukacja, rodzina, kultura. Studia z pedagogiki społecznej, Kraków 1999.

Bagrowicz J., Edukacja religijna współczesnej młodzieży. Źródła i cele, Toruń 2000.

Bartnik Cz., Personalizm, Lublin 1995.

Bilicka B., Kościół w polskich katechizmach i podręcznikach do nauki religii dla dzieci i młodzieży w latach 1945-2001, Toruń 2009.

Bravena N., Philosophizing with Children on National Tradition Related to Christmas, in: Symetrical communication? Philosophy and Theology in Classrooms across Europe, Hrsg. F. Kraft, H. Roose, G. Büttner, Loccum 2011, S. 61-74.

Davie G., Europe: The Exceptional Case. Parameters of Faith in the Modern World, London 2002. 
Duksa P., Strategie skuteczności szkolnego nauczania religii w Polsce. Studium pedagogicznoreligijne w wymiarze interdyscyplinarnym, Olsztyn 2007.

Gellel A., Adaptive Religious Education at the Service of Inventiveness: A scientific way of being creative and effective in Religious Education, "The Person and the Challenges" 1 (2011) Nr. 1, S. 99-111.

Gerjolj S., Ideologie und Bildung, Gießen 1997.

Hermeneutics and Religious Education, Hrsg. H. Lombaerts, D. Pollefeyt, Leuven-ParisDudley 2004.

Homplewicz J., Pedagogika rodziny. Zarys wykładów na podyplomowym studium prorodzinnym, Rzeszów 2000.

Kl’uska B., Idea chrześcijańskiego nawrócenia w procesie resocjalizacji, in: Socjalizacja - wyzwanie wspótczesności, Hrsg. J. Stala, Tarnów 2010, S. 75-87.

Lombaerts H., Edukacja z perspektywy europejskiej, „Horyzonty Wychowania” (2002) Nr 2, S. 165-179.

Lombaerts H., Komunikacja wiary dzisiaj, in: Komunikacja wiary w Trzecim Tysiacleciu, Hrsg. S. Dziekoński, Olecko 2000, S. 25-39.

Lombaerts H., Osewska E., Historical and Geo-Political Reality of a United Europe, in: S. Gatt, H. Lombaerts, E. Osewska, A. Scerri, Catholic Education, European and Maltese Perspectives. Church School's response to future challenges, Floriana 2004, S. $27-43$.

Lombaerts H., Osewska E., The Modern Christian Family as a First Setting for Religious and Moral Education?, in: Religious Education/Catechesis in the Family: A European Perspective, Hrsg. E. Osewska, J. Stala, Warszawa 2010, S. 11-25.

Lombaerts H., The Impact of the Status of Religion in Contemporary Society upon Interreligious Learning, in: Interreligious Learning, Hrsg. D. Pollefeyet, Leuven 2007, S. 81-86.

Mariański J., Johannes Paul II. als moralische Autorität in der polnischen Gesellschaft, "The Person and the Challenges" 2 (2012) Nr. 1, S. 21-50.

Osewska E., Edukacja religijna w szkole katolickiej w Anglii $i$ Walii $w$ świetle „Living and Sharing Our Faith. A National Project of Catechesis and Religious Education”, Tarnów 2008.

Osewska E., L'educazione oggi in un'Europa diversificata, in: Europa, scuola, religioni. Monoteismi e confessioni cristiane per una nuova cittadinanza europea, Hrsg. F. Pajer, Torino 2005, S. 47-64.

Osewska E., Le pèlegrinage à Czestochowa. Lieu d'éducation dans la foi, « Lumen Vitae Revue» (2007), S. 247-265.

Osewska E., Modele komunikacji interpersonalnej i ich znaczenie dla katechezy, in: Wybrane zagadnienia z katechetyki, Hrsg. J. Stala, Tarnów 2003, S. 111-142.

Osewska E., To Educate in a Diversified Europe, "The Person and the Challenges" 1 (2011) Nr. 1, S. 71-88.

Osewska E., Wychowanie młodzieży w świetle Programu Polityki Rodzinnej państwa, in: Dzisiejszy bierzmowany. Problemy i wyzwania, Hrsg. J. Stala, Kielce 2005, S. 455-466.

Prijatelj E., Geistige Dynamik von Vorschulkindern und deren Einführung in den Glauben, „Christlich pädagogische Blätter” (2007) Nr. 2, S. 100-104.

Prijatelj E., Psihološka dinamika rasti v veri, Ljubljana 2008. 
Rossiter G., Reasons for Living. Religious Education and Young People's Search for Spirituality and Identity, in: Religious Education as Practical Theology, Hrsg. B. Roebben, M. Warren, Leuven-Paris-Sterling 2001.

Skreczko A., Rola Kościoła katolickiego w ksztattowaniu kultury pedagogicznej rodziców w Polsce, Białystok 2011.

Skreczko A., Troska Kościoła katolickiego w Polsce o matżeństwo i rodzine $w$ okresie Wielkiej Nowenny Tysiaclecia (1957-1966). Studium teologiczno-pastoralne, Białystok 2002.

Stala J., Der Mensch als Person: Die bestimmende Grundlage für Johannes Paul II. in seinem Bild von der Familie, ,The Person and the Challenges” 2 (2012) Nr. 2, S. 41-59.

Stala J., Die Erzieherischen Umfelder und Ihre Rolle im Rahmen der Erziehungsaufgaben, „Studia Teologiczno-Historyczno Śląska Opolskiego” 27 (2007), S. 375-383.

Stala J., Die Transzendenz als bestimmendes Merkmal der Person in der Anthropologie und der Pädagogik Johannes Pauls II., „The Person and the Challenges” 2 (2012) Nr. 1, S. 61-75.

Stala J., Familie und Schule: Zwei Erziehungsumfelder und ihre Rolle im Rahmen der Erziehung, „Roczniki Teologiczne” 55 (2008), Tom 8, S. 101-112.

Stala J., Familienkatechese in Polen um die Jahrhundertwende. Probleme und Herausforderungen, Tarnów 2008.

Stala J., Osewska E., Anders erziehen in Polen. Der Erziehungs- und Bildungsbegriff im Kontext eines sich ständig verändernden Europas des XXI. Jahrhunderts, Tarnów 2009.

Stala J., Osewska E., Sociological Aspects of Family Religious Education in Poland, in: Religious Education / Catechesis in the Family. A European Perspective, Hrsg. E. Osewska, J. Stala, Warszawa 2010, S. 167-177.

Szostek A., Wokót godności prawdy i miłości, Lublin 1998.

Vodičar J., Muss man die Globalisierung unterrichten?, „Synthesis Philosophica” (2009) 2, S. 281-295.

Wilk J., Pedagogika rodziny. Zagadnienia wybrane, Lublin 2002.

Wojtyła K., Rozważania o istocie człowieka, Kraków 1999. 